\section{Mapping Genes Governing Flower and Seedcoat Color in Asparagus Bean (Vigna unguiculata ssp. sesquipedalis) Based on Single Nucleotide Polymorphism and Simple Sequence Repeat Markers}

Pei $\mathrm{Xu}^{1}$, Tingting $\mathrm{Hu}^{1}$, Yuejian Yang, Xiaohua Wu, Baogen Wang, Yonghua Liu, and Dehui Qin

Institute of Vegetables, Zhejiang Academy of Agricultural Sciences, 310021 Hangzhou, People's Republic of China

Jeffrey Ehlers and Timothy Close

Department of Botany and Plant Sciences, University of California, Riverside, CA 92521-0124

\section{Zhongfu Lu and Guojing $\mathbf{L i}^{2}$ \\ Institute of Vegetables, Zhejiang Academy of Agricultural Sciences, 310021 Hangzhou, People's Republic of China}

Additional index words. asparagus bean, flower color, seedcoat color, linkage mapping, synteny

Abstract. Colors of flower and seedcoat are interesting traits of asparagus bean, a cultivated subspecies of cowpea grown throughout Asia for its tender, long green pods. Little is known about the inheritance of these traits including their genome location. We report here the genetic analysis and mapping of the genes governing flower and seedcoat color in asparagus bean based on single nucleotide polymorphism (SNP) and simple sequence repeat (SSR) markers. Analysis of the $F_{1}$ and $F_{7: 8}$ generation of recombinant inbred lines (RILs) population showed a monogenetic inheritance of both traits. Purple flower and brown seedcoat are dominant over white flower and cream seedcoat, respectively. We further show that genes governing flower color and seedcoat color are tightly linked on LG8, $\approx 0.4 \mathrm{cM}$ apart. Synteny analysis showed that the gene controlling seedcoat color in our study is syntenic to the soybean $T$ locus. The use of the mapping information in asparagus bean breeding is discussed.

Cowpea (Vigna unguiculata L. Walp.) $(2 \mathrm{n}=$ $2 \mathrm{x}=22$ ), a self-pollinating diploid species belonging to the genus Vigna of the Phaseoleae tribe, is an important food legume worldwide. Two main cultivated divisions of cowpea are the ssp. unguiculata and ssp. sesquipedalis. Subspecies unguiculata is the largest cowpea group grown primarily for dry grain and fodder, providing millions of people in Africa, India, the Middle East, and South America with high-protein food stuff (Ehlers and Hall, 1997; Singh, 2002). The ssp. sesqui-

Received for publication 18 Apr. 2011. Accepted for publication 2 June 2011.

This study was partially supported by the National Science Foundation of China (No. 30871711, 30900985), the Science Foundation of Zhejiang Province (No. Y3090146), and the Sino-U.S. joint project funded by Zhejiang Academy of Agricultural Sciences.

${ }^{1}$ These authors contributed equally to this article.

${ }^{2}$ To whom reprint requests should be addressed; e-mail Guojing_li@Yahoo.com.cn. because an investigation of $\approx 1000$ asparagus bean accessions from various origins of China typically detected only three major types of principal flower color, which are purple, white, and tinged (Wang BG, personal communication). In terms of seedcoat color, a wide range of variations, including black, white or cream, brown, yellow, and red are found in both subspecies.

The inheritance mode of cowpea flower coloring is genotype-dependent. A monogenic inheritance with complete dominance (Padi, 2003; Sangwan and Lodhi, 1998), an interaction of two genes in a complementary manner and an involvement of two genes epistatically interacting were reported in ssp. unguiculata (Mustapha, 2007). A general color factor $C$ is considered responsible for seedcoat color and its absence results in white seeds (Spillman, 1912). In some genotypes, the $C$ factor in combination with other genes conditions certain colors of seedcoat. Spillman and Sando (1930) proposed that six major genes $(R, P, B, M, N$, $U$ ) were involved in different ssp. unguiculata parental lines controlling seedcoat color. What is also worthy to note is that seedcoat color is inherently independent of the seedcoat "eye" pattern, the latter of which usually complicated phenotyping of seedcoat color (Calub, 1968; Kehinde et al., 1997). There has been no report on genetic analysis of flower and seedcoat pigmentation in asparagus bean so far.

Flower and seedcoat coloring is in some cases highly related. Saunders (1960) reported that purple flowers were associated with selfcolored or pigmented seedcoats, whereas white flowers were associated with cream/white seedcoat in general. A general flower color factor $\mathrm{C}$ has been mapped onto the fourth linkage group of ssp. unguiculata based on amplified fragment length polymorphism (AFLP) markers (Menéndez et al., 1997); however, the location of genes conferring seedcoat color still remains unknown. In this article, we report the inheritance and mapping of the genes controlling flower and seedcoat color in asparagus bean based on our newly constructed asparagus bean reference genetic map (the ' $\mathrm{ZZ}$ ' map), which is enriched with expressed sequence tag (EST)-derived SNPs and SSR markers (Xu et al., 2011).

\section{Materials and Methods}

Plant materials included 'ZN016', a landrace of asparagus bean originating from southern China, 'Zhijiang 28-2', a commercial cultivar in China, their $F_{1}, F_{2}$, and the $F_{7: 8}$ generation of RILs population consisting of 209 lines. 'ZN016' is white-flowered and cream-seedcoated, whereas 'Zhijiang 28-2' has purple flowers and a brown seedcoat. A completely randomized block design was used having two replicates. For each line, eight to 10 seeds were sown but only four were retained after seedling emergence.

The color of the flower and seedcoat was scored visually. Given that not all the lines flowered at the same day and that color of aged flowers may be confusing, data were 
Table 1. Segregation of flower and seedcoat color in an $F_{1}$ and recombinant inbred line population.

\begin{tabular}{|c|c|c|c|c|c|c|c|c|c|c|}
\hline \multirow[b]{3}{*}{ Generation } & \multicolumn{5}{|c|}{ Flower color } & \multicolumn{5}{|c|}{ Seedcoat color ${ }^{z}$} \\
\hline & \multicolumn{2}{|c|}{ No. of lines } & \multirow{2}{*}{$\begin{array}{c}\text { Expected } \\
\text { ratio }\end{array}$} & \multirow[b]{2}{*}{$\chi^{2}$} & \multirow[b]{2}{*}{$P$} & \multicolumn{2}{|c|}{ No. of lines } & \multirow{2}{*}{$\begin{array}{l}\text { Expected } \\
\text { ratio }\end{array}$} & \multirow[b]{2}{*}{$\chi^{2}$} & \multirow[b]{2}{*}{$P$} \\
\hline & Purple & White & & & & Brown & Cream & & & \\
\hline$\overline{F_{1}}$ & 9 & 0 & - & - & - & 9 & 0 & - & - & - \\
\hline $\mathrm{F}_{7: 8}$ & 88 & 115 & $1: 1$ & 3.59 & $0.05-0.1$ & 89 & 114 & $1: 1$ & 3.08 & $0.05-0.1$ \\
\hline
\end{tabular}

${ }^{\mathrm{z}}$ For color of seedcoat, which is maternal tissue, the seeds surveyed were $\mathrm{F}_{2}$ families derived from the nine $\mathrm{F}_{1}$ individuals.

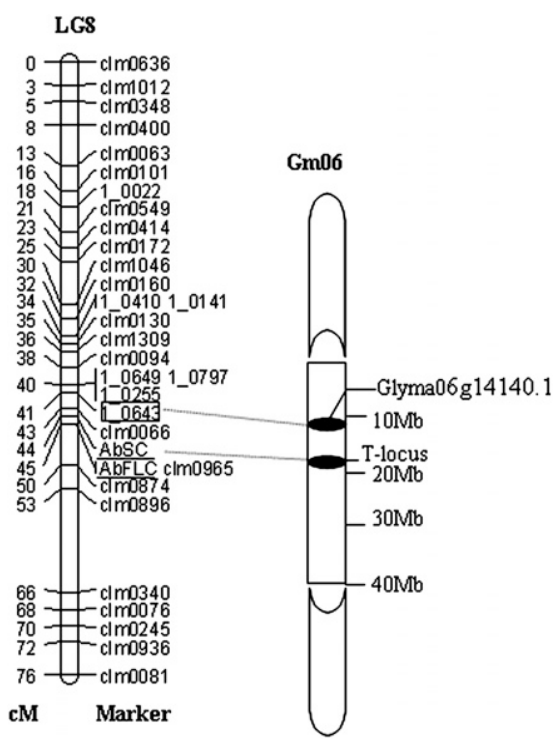

Fig. 1 Linkage mapping of the $a b F L C$ and $a b S C$ loci and their synteny to soybean chromosome 6. (Left) The asparagus bean LG8. Underlined are the $a b F L C$ and $a b S C$ loci; boxed is the single nucleotide polymorphism locus 1_0643. (Right) A regional-magnified schematic show of soybean chromosome 6 .

recorded daily for freshly flowered lines until the latest flowering line had flowered.

Basic statistical analysis, including frequency distribution, chi-square test, and analysis of variance, was conducted with STATISTICA 5.5. The segregation data of each trait was treated as from a single locus and the genes were mapped onto the SNP and SSR markersbased genetic map (Xu et al., 2011), in which linkage group nomenclature is corresponding to the cowpea consensus map (Muchero et al., 2009) using the software Joinmap 3.0. The limit of detection significance and recombination rate threshold were set as 2.0 and 0.4 , respectively. The Kosambi function was used to calculate the genetic distance.

\section{Results and Discussion}

Nine $F_{1}$ plants uniformly exhibited a purple flower. Color of seedcoat, which is maternal tissue, was found uniformly brown through investigating the nine $F_{2}$ families harvested from the nine $F_{1}$ individuals, indicating a dominant nature of purple flower over white flower and brown seedcoat over white seedcoat, respectively. The segregation of individual RIL lines in the two replicates was very consistent with only two between-replicate (line Nos. 71, 160) discrepancies and four lines showing variable expression (lines 27, $106,142,199)$, which means for a given RIL line, the flower or seedcoat color from different plants was inconsistent and thus was considered probably the result of residual heterozygosity or mishandling of seeds. Data from these six lines were hereafter excluded from further analysis. The segregation data for flower and seedcoat color for the remaining 203 lines, as shown in Table 1, both fit a 1:1 ratio, suggesting monogenic control of both traits.

Because only 96 lines of the RIL population were genotyped for linkage mapping (Xu et al., 2011) within which Nos. 27 and 160 should be removed as stated before, the fit of segregation was also tested using the 94-line subset. For both traits, data from the subset fit a 1:1 model, with a chi-squared value of 0.17 and 0.04 , respectively. These data were subsequently used in genetic mapping. As a result, the genes controlling flower and seedcoat color were mapped onto the distal region of LG8 and were tightly linked (Fig. 1) with a genetic distance of $0.4 \mathrm{cM}$ caused by only one crossover observed in line No. 136. These gene loci were temporally named $a b F L C$ and $a b S C$, respectively.

The monogenic dominance of purple over white flower observed in our population is consistent with some previous reports from ssp. unguiculata (Kehinde et al., 1997; Sangwan and Lodhi, 1998). Single dominant gene inheritance of brown over cream seedcoat color in ssp. unguiculata was also reported by Padi (2003). The simple nature of inheritance of the traits made it ideal for mapping genes using this population. Our result showed that flower and seedcoat coloring are controlled by different but closely linked loci, which is in agreement with the result of Kehinde et al. (1997) from ssp. unguiculata; however, Padi (2003) suggested that in some cases, flower and seedcoat pigmentation is controlled by the same locus. Thus, the mechanism of flower and seedcoat coloring is dependent on the parental lines used. An alternative explanation is that in some studies, crossovers were not observed in the population sample used.

Because the genes abFLC and $a b S C$ were mapped onto LG8, they are different loci from the general color factor $\mathrm{C}$ that was previously mapped onto the AFLP-based LG4 corresponding to the cowpea consensus map LG1 and LG2 (Menéndez et al., 1997; Ouédraogo et al., 2002). In common bean (Phaseolus vulgaris L.), a major dominant gene (gene $P / p$ ) mapped at LG7 was involved in the genetic control of both traits. According to the common bean-soybean synteny (McClean et al., 2010), this gene is not in the same chromosome corresponding to the asparagus bean LG8. Therefore, the $a b F L C$ and $a b S C$ genes are also different from the $P / p$ locus. This is consistent with the different effects of the $a b F L C / a b S C$ and $P / p$ genes (independent versus pleiotrophic effects). In soybean, the T locus determining seedcoat color was mapped onto LGC2 (chromosome 6), which is syntenic to the cowpea LG8 (Muchero et al., 2009). When the EST-derived SNP marker 1_0643 that is tightly linked to abSC is blastsearched against the soybean genome, this marker is syntenic (e-value $\left.=7.7 \times \mathrm{e}^{-107}\right)$ to the soybean gene locus Glyma06g14140.1 with only $\approx 7 \mathrm{Mb}$ physical distance to the $\mathrm{T}$ locus (Fig. 1). Therefore, it is very likely that the abSC locus is syntenic to the soybean $\mathrm{T}$ locus. Additional work is needed to further validate this assumption.

The mapping of the genes controlling flower and seedcoat color serves as the first step to precisely dissect the genetic nature of these important traits in cowpea and related species. Because a lot of information about genes controlling flower and seedcoat color is available from model species and plenty of DNA sequence resources are available for cowpea/ asparagus bean, in the near future, it will be feasible to fine map and isolate the $a b F L C$ and $a b S C$ genes through a comparative genomicsbased approach. For breeders, the mapping information will help understand linkage relationships among these and other important agronomic traits to more strategically plan crosses and determine appropriate population sizes to recover desired recombinants. Similarly, flower and/or seedcoat color could be used as convenient phenotypic markers to help select desired traits.

\section{Literature Cited}

Calub, A.G. 1968. Inheritance of seed coat colour and colour pattern in Vigna sinensis. MS thesis, University of the Philippines, college of agriculture. In: Cowpea: Abstract of world literature 14. UTA, Ibadan, Nigeria.

Drabo, I., T.A.O. Ladeinde, J.B. Smithson, and R. Redden. 1987. Inheritance of eye pattern and seed coat colour in cowpea Vigna unguiculata L. Walp. Plant Breed. 100:119-123.

Ehlers, J.D. and A.E. Hall. 1997. Cowpea Vigna unguiculata L. Walp. Field Crops Res. 53:187204.

Kehinde, O.B., G.O. Myers, and I. Fawole. 1997. Analysis of genetic linkage in the cowpea Vigna unguiculata. Pertanika, J. Trop. Agr. Sci. 20: 75-82.

Langyintuo, A.S., J. Lowenberg-DeBoer, M. Faye, D. Lambert, G. Ibro, B. Moussa, A. Kergna, S Kushwaha, S. Musa, and G. Ntoukam. 2003. Cowpea supply and demand in west and central Africa. Field Crops Res. 82:215-231.

Leleji, O.I. 1972. Apparent preference by bees for different flower colours in cowpeas. Euphytica 22:150-153

McClean, P.E., S. Mamidi, M. McConnell, S Chikara, and R. Lee. 2010. Synteny mapping between common bean and soybean reveals extensive blocks of shared loci. BMC Genomics 11:184.

Menéndez, C.M., A.E. Hall, and P. Gepts. 1997. A genetic linkage map of cowpea Vigna unguiculata developed from a cross between two 
inbred, domesticated lines. Theor. Appl. Genet. 95:1210-1217.

Muchero, M., N.N. Diop, P.R. Bhat, R.D. Fenton, S. Wanamaker, M. Pottorff, S. Hearne, N. Cisse, C. Fatokun, J.D. Ehlers, P.A. Roberts, and T.J. Close. 2009. A consensus genetic map of cowpea [Vigna unguiculata L. Walp] and synteny based on EST-derived SNPs. Proc. Natl. Acad. Sci. USA 106:18159-18164.

Mustapha, Y. 2007. Inheritance of flower colour in cowpea [Vigna unguiculata L. Walp]. IJPAS $1: 10-19$.

Ouédraogo, J.T., B.S. Gowda, M. Jean, T.J. Close, J.D. Ehlers, A.E. Hall, A.G. Gillaspie, P.A. Roberts, A.M. Ismail, G. Bruening, P. Gepts, M.P. Timko, and F.J. Belzile. 2002. An improved genetic linkage map for cowpea (Vigna unguiculata L.) combining AFLP, RFLP, RAPD, biochemical markers, and biological resistance traits. Genome 45:175-188.
Padi, F.K. 2003. Genetic analyses of pigmentation in cowpea. Pak. J. Biol. Sci. 6:1655-1659.

Rachie, K.O. 1985. Introduction, p. xxi-xxvii. In: Singh, S.R. and K.O. Rachie (eds.). Cowpea research, production, and utilisation. International Institute of Tropical Agriculture IITA, Ibadan, Nigeria.

Sangwan, R.S. and G.P. Lodhi. 1998. Inheritance of flower and pod colour in cowpea Vigna unguiculata L. Walp. Euphytica 102: 191-193.

Saunders, A.R. 1960. Inheritance in the cowpea Vigna sinensis Endb. 2. Seed coat colour, pattern, flower, pod colour. S. Afr. J. Agr. Sci. 3:141-162.

Singh, B.B. 2002. Recent genetic studies in cowpea, p. 3-13. In: Fatokun, C.A., S.A. Tarawali, B.B. Singh, P.M. Kormawa, and M. Tamo (eds.). Challenges and opportunities for enhancing sustainable cowpea production. International Institute of Tropical Agriculture, Ibadan, Nigeria.
Spillman, W.J. 1912. As cited in: Fery, R.L. 1980. Genetics of vigna. Hort. Rev. 2:311-394.

Spillman, W.J. and W.J. Sando. 1930. Mendelian factors in cowpea Vigna species. Mich. Acad Sci. Arts and Letters Papers 11:249-283.

Xu, P., X.H. Wu, B.G. Wang, Y.H. Liu, J.D. Ehlers, T.J. Close, P.A. Roberts, N.-N. Diop, D.H. Qin, T.T. Hu, Z.F. Lu, and G.J. Li. 2011. A SNP and SSR based genetic map of asparagus bean (Vigna. unguiculata ssp. sesquipedialis) and comparison with the broader species. PLoS ONE 6:E15952.

Xu, P., X.H. Wu, B.G. Wang, Y.H. Liu, D.H. Qin, J.D. Ehlers, T.J. Close, T.T. Hu, Z.F. Lu, and G.J. Li. 2010. Development and polymorphism of Vigna unguiculata ssp. unguiculata microsatellite markers used for phylogenetic analysis in asparagus bean Vigna unguiculata ssp. sesquipedialis L. Verdc. Mol. Breed. 25:675684 . 